DOI: $10.4274 /$ jarem.galenos.2020.3579

J Acad Res Med 2020;10(3):277-82

\title{
Reliability and Validity of the Turkish Version of the Questionnaire for the Assessment of Self-Reported Olfactory Functioning and Olfaction-Related Quality of Life
}

\author{
(1) Özlem Saatçi1', (1) Özge Arııı Düz², (1) Aytuğ Altundağ³ \\ ${ }^{1}$ University of Health Sciences Turkey, Sancaktepe Şehit Prof Dr. İlhan Varank Training and Research Hospital, Clinic of Otolaryngology, \\ İstanbul, Turkey \\ ${ }^{2}$ Medipol University Faculty of Medicine, Department of Neurology, İstanbul, Turkey \\ ${ }^{3}$ Biruni University Faculty of Medicine, Department of Otolaryngology, İstanbul, Turkey
}

Cite this article as: Saatçi Ö, Arıcı Düz Ö, Altundağ A. Reliability and Validity of the Turkish Version of the Questionnaire for the Assessment of SelfReported Olfactory Functioning and Olfaction-Related Quality of Life. J Acad Res Med 2020;10(3):277-82

\begin{abstract}
Objective: To examine the reliability and validity of the Turkish version of the questionnaire for the assessment of self-reported olfactory functioning and olfaction-related quality of life (ASOF).

Methods: Three different surveys [ASOF, beck depression inventory (BDI), and 36-Item Short-Form Health Survey (SF-36) questionnaire] were completed by 112 subjects with subjective olfactory dysfunction (OD) and 21 healthy controls. Sniffin' Sticks tests were performed. Internal consistency, test-retest reliability, and validity were analyzed.

Results: The Cronbach $\alpha$ coefficients for the ASOF self-reported capability of perceiving (ASOF-SRP) specific odors scale (SOC) and ASOF selfreported olfaction-related quality of life (ASOF-ORQ) were 0.98 and 0.97 , with relatively high internal consistency, respectively. The test-retest reliability for the ASOF was high for all subscales. ASOF-SRP-SOC, ASOF-SRP, and ASOF-ORQ showed significant positive correlations with the overall SF-36 score and negative correlations with BDI. The ASOF scale scores in healthy controls were significantly higher than those in patients with hyposmia and anosmia ( $p=0.001$ ). TDI composite score and its subscales (threshold, discrimination, and identification) showed significant negative correlations with the BDI score and significant positive correlations with each of the SF-36 domains and overall SF-36 scores and ASOF subtests.

Conclusion: This study showed that the Turkish version of the ASOF is a reliable and valid measure to determine the olfactory function and impairment in daily life associated with OD. Because of the easy-to-use features of the ASOF, it is a useful tool for initial assessment and follow-up of the subjects with OD.

Keywords: Smell, olfaction disorders, quality of life, olfactory test, olfaction-related quality of life, questionnaire of olfactory disorders
\end{abstract}

\section{INTRODUCTION}

The prevalence of olfactory dysfunction (OD) in the general population ranges between $4 \%$ and $25 \%$ (1). Sinonasal disorders, upper airway infections, and trauma are the most frequent causes of $O D$ (2). OD not only leads to a decline in tasting foods, but also may affect an individuals' life by complicating the recognition of rotten food or toxic gases (3). Moreover, OD may influence subjects' well-being and health-related quality of life and may even lead to the development of depression in some individuals (4).

ORCID IDs of the authors: Ö.S. 0000-0002-3372-9514; Ö.A.D. 0000-0003-0334-811X; A.A.0000-0003-0794-5050. 
Psychometric assessment tools have been developed to evaluate the individual effects of OD on daily activities. Questionnaire for olfactory dysfunction (QOD), olfaction questionnaire, and assessment of self-reported olfactory functioning and olfactionrelated quality of life (ASOF) are some of the tests used to evaluate the functional status and health-related quality of life following OD (3-7). ASOF was developed by Pusswald et al. (4) in 2012. ASOF contains subjective olfactory capability scale (SOC), selfreported capability of perceiving specific odors scale (SRP), and olfactory-related quality of life scale (ORQ). Besides its feasibility for application to subjects with OD, ASOF can also provide data concerning the psychometric properties of subjects with OD. ASOF, which is used to assess patients' subjective symptom severity in clinical practice, has been shown to discriminate between subjects with normosmia and hyposmia $(8,9)$.

Disease-specific questionnaires evaluating the quality of life may be utilized to identify the changes in the health-related quality of life. Moreover, these inventories may help compare data derived from different populations. However, the content and language of the questionnaires have to be adapted and tested before its application in different patient populations. Therefore, the present study aimed to assess the validity and reliability of the Turkish version of the ASOF in subjects with OD.

\section{METHODS}

This prospective single-center study was conducted on 112 subjects admitted to the Smell and Taste Center for subjective smell disorders between March 2019 and December 2019. The control group included 21 healthy subjects without any chronic medical disease or OD. All subjects underwent routine otolaryngological examination, nasal endoscopy, computed tomography of the paranasal sinuses, and Sniffin' Sticks test. Subjects with neurodegenerative diseases, pregnant subjects, smokers, and subjects with malignancies were excluded. Ethics committee approval was received for this study from the Ethics Committee of Medipol University (approval number: 268, date: 22.03.2019). The study was conducted in accordance with the ethical standards in the 1964 Declaration of Helsinki and its later amendments. Informed consent was obtained from all individual participants included in the study.

In the test-retest reliability analysis, the data related to 50 individuals were analyzed through the Spearman correlation test and compared with the data obtained after 3 weeks.

\section{Olfactory Function Tests}

The Turkish version of the Sniffin' Sticks test (Burghart, Wedel, Germany) was used to evaluate patients' olfactory function. The cap of the pen was removed by the experimenter to present odor for $3 \mathrm{~s}$ while the tip of the pen was $1-2 \mathrm{~cm}$ away from the nostrils. Odor thresholds (T) for $n$-butanol were determined by using three alternative forced-choice procedures. Sixteen triplets of pens were presented for odor discrimination (D), one containing $4 \%$ n-butanol solution (target odorant), and the other two containing only propylene glycol (negative controls). The subjects were requested to identify the pen containing the odorant. Each odor was presented once. The subjects were blindfolded using a sleeping mask to prevent visual identification of the pens. At least 30-s intervals were provided between odor samplings. The answer was accepted as correct when the subject could identify the pen containing the odorant for two consecutive applications. T was scored from 1 to 16 .

Sixteen common odors were used to assess odor identification (OI). OI was performed from a list of four verbal descriptors using a multiple forced-choice paradigm. Each odorant was presented by the experimenter with 30-s intervals between odors. OI was scored from 0 to 16 .

Overall olfactory function (TDI score) was expressed by adding the scores from the three individual tests, and scores of $<16.5$ and $>30.5$ correspond to functional anosmia and normosmia, respectively (10). Subjects with a TDI score between 16.5 and 30.5 were considered to have hyposmia (11).

\section{Translation and Scoring of ASOF}

The necessary legal permission to translate the ASOF inventory to the Turkish language was obtained from Johann Lehrner by e-mail. The ASOF inventory was translated to Turkish by two independent medical translators (4). The translated inventory was approved by five ear, nose, and throat specialists who were aware of the socio-cultural properties of the study group. The Turkish version of the ASOF inventory was then retranslated to English by two independent medical translators unaware of the original ASOF inventory. A committee consisting of specialists checked the English version, and this version was resent to the authors for approval.

The original version of the ASOF consisted of three domains, including the one-item SOC, the five-item SRP, and the six-item $\mathrm{ORO}$ scales. SOC indicates the olfactory performance on a Likert scale ranging from 0 to 10 ( 0 indicates unable to smell and 10 indicates best possible smell). An SOC score of $\leq 3$ indicates abnormal olfactory capabilities. SRP includes five items and measures the capability of perceiving specific odors. An SRP score of $\leq 2.9$ indicates problems in smelling odors. The six-item ORQ measures olfaction-related quality of life. Patients with $\mathrm{ORQ}$ score of $\leq 3.7$ are considered to have smell-related problems in their quality of life.

In the test-retest reliability analysis, the data related to 50 individuals were analyzed through the Spearman correlation test and compared with the data obtained after 3 weeks.

To assess the validity of the Turkish version of the ASOF, its correlation with other psychometric tests, such as the 36-Item Short-Form Health Survey questionnaire (SF-36), and beck depression inventory (BDI) was analyzed.

\section{SF-36}

The SF-36 is a multi-item scale that assesses the limitations in eight health concepts, including limitations in physical and social activities, and usual role activities caused by physical or emotional problems $(12,13)$. 


\section{BDI}

The BDI consists of 21 self-scored items that evaluate key symptoms of depression. Scores between 10 and 16, between 17 and 23 , and $\geq 24$ indicate mild, moderate, and severe depression, respectively $(14,15)$.

\section{Statistical Analysis}

All analyses were performed using SPSS v21 (SPSS Inc., Chicago, IL, USA). Shapiro-Wilk test was used to test data distribution. Descriptive data were expressed as mean \pm standard deviation, and categorical variables were presented as frequency and percentages. The Cronbach alpha coefficient was calculated to assess the internal consistency of the ASOF and its subscales. The test-retest reliability was calculated by correlating initial and subsequent test scores based on the Spearman correlation coefficient.

The convergent validity of the ASOF and its subscales was assessed by correlating their scores with SF-36 and BDI using the Spearman's rank coefficient of correlation. The discriminative validity of the ASOF was evaluated by comparing its scores between subgroups of patients with anosmia, hyposmia, and normosmia by using the Kruskal-Wallis test. The correlation of the ASOF with TDI score and its subscales (T, D, and OI) was evaluated using the Spearman's rank correlation coefficient. The association of the ASOF subtests with patients' sex and age was also examined using the Mann-Whitney U Test and Spearman's rank correlation coefficient, respectively. Two-tailed $\mathrm{p}<0.05$ was accepted as statistically significant.

\section{RESULTS}

The study enrolled 133 subjects (mean age: $44.83 \pm 13.15$ years), $46.5 \%$ of the subjects were men. Hyposmia and anosmia were noted in 54 (48.2\%) and 58 (51.8\%) participants. The control groups consisted of 21 healthy volunteers. The etiology was chronic rhinosinusitis, allergic rhinitis, post-upper respiratory tract infection, and post-traumatic in 29 (25.9\%), 24 (21.4\%), 42 (37.5\%), and in 17 (15.2\%) subjects, respectively. The duration of olfactory loss was $29.71 \pm 9.92$ months.

The Cronbach $\alpha$ coefficients calculated for the ASOF-SRP and ASOF-ORQ in all patients were 0.98 and 0.97 , with relatively high internal consistency, respectively.

The test-retest reliability coefficient for subscales were 0.97 $(p<0.001)$ and $0.94(p<0.001)$ for ASOF-SRP and ASOF-ORQ, respectively.

For validation, we assessed both convergent and discriminant validity. The convergent validity of the ASOF subscales (SOC, SRP, and $\mathrm{ORQ}$ ) were assessed by correlating their scores with other validated psychometric tests. ASOF-SOC, ASOF-SRP, and ASOFORQ showed significant positive correlations with all SF-36 score and SF-36 domains, and negative correlations with BDI (Table 1). The discriminant validity of the ASOF was evaluated by comparing ASOF-SOC, ASOF-SRP, and ASOF-ORQ scores in patients with different olfactory functions (anosmia, hyposmia, and normosmia). ASOF-SOC, ASOF-SRP, and ASOF-ORQ scores in healthy controls were significantly higher than those in patients with hyposmia and anosmia ( $p=0.001$ ). ASOF-SOC, ASOF-SRP, and ASOF-ORO scores in patients with hyposmia were also higher than those in patients with anosmia ( $p=0.001$ ) (Table 2, Figure 1). In addition, all SF-36 domain scores in healthy controls were higher than those in patients with hyposmia and anosmia $(p<0.001)$. Moreover, the $\mathrm{BDI}$ score in healthy controls was significantly lower than that in patients with hyposmia and anosmia $(p<0.001)$.

Statistically significant negative correlations of $T, D, O I$, and TDI scores with the $\mathrm{BDI}$ score and statistically significant positive correlations of T, D, OI, and TDI scores with each of the SF-36 domains and overall SF-36 scores were noted. TDI score and its subscales (T, D, and OI) were also positively correlated with ASOFSOC, ASOF-SRP, and ASOF-ORQ scores (Table 3). However, no significant correlations were observed between age and ASOF-

\section{Table 1. Correlation between ASOF test with SF-36 and BDI}

\begin{tabular}{|c|c|c|c|c|c|c|}
\hline & \multicolumn{2}{|c|}{ ASOF-SOC } & \multicolumn{2}{|c|}{ ASOF-SRP } & \multicolumn{2}{|c|}{ ASOF-ORO } \\
\hline & $r$ & $p$ & $r$ & $p$ & $r$ & $p$ \\
\hline PF & 0.620 & $<0.001$ & 0.454 & $<0.001$ & 0.445 & $<0.001$ \\
\hline RE & 0.622 & $<0.001$ & 0.513 & $<0.001$ & 0.432 & $<0.001$ \\
\hline VT & 0.699 & $<0.001$ & 0.658 & $<0.001$ & 0.655 & $<0.001$ \\
\hline SF & 0.603 & $<0.001$ & 0.604 & $<0.001$ & 0.595 & $<0.001$ \\
\hline $\mathrm{BP}$ & 0.696 & $<0.001$ & 0.703 & $<0.001$ & 0.722 & $<0.001$ \\
\hline $\mathrm{GH}$ & 0.702 & $<0.001$ & 0.601 & $<0.001$ & 0.639 & $<0.001$ \\
\hline BDI & -0.634 & $<0.001$ & -0.585 & $<0.001$ & -0.564 & $<0.001$ \\
\hline
\end{tabular}


Table 2. Comparison of ASOF scores between healthy control and patients with hyposmia and anosmia

\begin{tabular}{|l|l|l|l|l|l|l|}
\hline & $\begin{array}{l}\text { Healthy controls } \\
(\mathbf{n = 2 1 )}\end{array}$ & $\begin{array}{l}\text { Patients with hyposmia } \\
(\mathbf{n = 5 4 )}\end{array}$ & $\begin{array}{l}\text { Patients with } \\
\text { anosmia (n=58) }\end{array}$ & $\mathbf{p}^{\mathbf{1}}$ & $\mathbf{p}^{\mathbf{2}}$ & $\mathbf{p}^{\mathbf{3}}$ \\
\hline ASOF-SOC & $7.62 \pm 0.8$ & $2.85 \pm 1$ & $1.84 \pm 1.02$ & $<0.001$ & $<0.001$ & $<0.001$ \\
\hline ASOF-SRP & $4.93 \pm 0.22$ & $2.8 \pm 0.56$ & $2.06 \pm 0.48$ & $<0.001$ & $<0.001$ & $<0.001$ \\
\hline ASOF-ORO & $4.93 \pm 0.23$ & $2.77 \pm 0.53$ & $2.6 \pm 0.33$ & $<0.001$ & $<0.001$ & $<0.001$ \\
\hline
\end{tabular}

Data expressed as mean \pm standard deviation.

ASOF-SOC: self-reported capability of perceiving specific odors scale, ASOF-SRP: self-reported capability of perceiving specific odors scale, ASOF-ORO: self-reported olfaction related quality of life, $p^{1}$ : control group vs group with hyposmia $(p=0.001 ; p<0.01), p^{2}$ : control group vs group with anosmia ( $\left.p=0.001 ; p<0.01\right)$, $p^{3}$ : groups with hyposmia vs anosmia $(p=0.001 ; p<0.01)$

Table 3. Correlation of ASOF test, SF-36 test and BDI test with olfactory tests (TDI score and its subtests OT, OD, and OI)

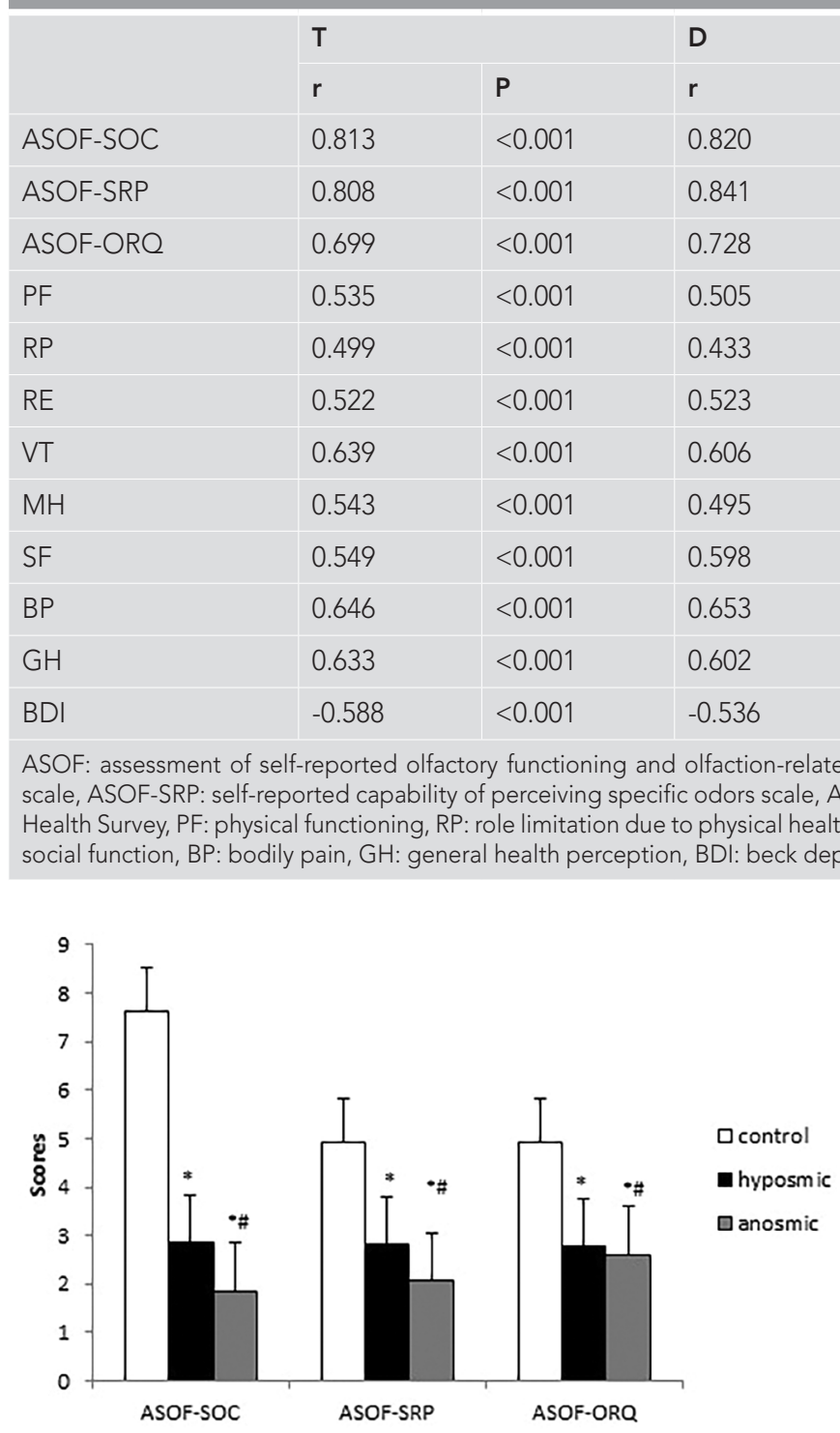

Figure 1. Comparison of ASOF scores between healthy control and patients with hyposmia and anosmia

${ }^{*} p<0.05$ in comparison of the control group vs. the groups with hyposmia and anosmia, $\# p<0.05$ in comparison of the groups with hyposmia vs anosmia, ASOF: assessment of self-reported olfactory functioning and olfaction-related quality of life, ASOF-SOC: self-reported capability of perceiving specific odors scale, ASOF-SRP: self-reported capability of perceiving specific odors scale, ASOF-ORQ: self-reported olfaction related quality of life
SOC, ASOF-SRP, and ASOF-ORQ scores ( $p=0.773 ; p=0.60$; $p=0.921$, respectively). ASOF-SOC, ASOF-SRP, and ASOF-ORO scores were also similar in male and female participants $(p=0.347$; $p=0.268 ; p=0.435$, respectively)

\section{DISCUSSION}

This study showed that the Turkish version of the ASOF is highly reliable and valid to assess the subjective severity of $O D$ in a Turkish population. The Cronbach $\alpha$ coefficients calculated for the ASOF-SRP and ASOF-ORQ in all patients were 0.98 and 0.97, respectively. The test-retest reliability for subscales also ranged between 0.94 and 0.97 , suggesting that the ASOF has high reproducibility. Thus, test-retest reliability was found to be acceptable for ASOF. The significant correlations between ASOFSOC, ASOF-SRP, and ASOF-ORO with overall SF-36 score and SF-36 domains, and significant negative correlations between ASOF-SOC, ASOF-SRP, and ASOF-ORQ with BDI showed the convergent validity of the ASOF subscales. ASOF-SOC, ASOFSRP, and ASOF-ORQ scores differed significantly among healthy 
controls and patients with hyposmia and anosmia, indicating discriminant validity of the ASOF subscales. TDI score and its subscales (T, D, and OI) showed significant negative correlations with the BDI score and significant positive correlations with each of the SF-36 domains and overall SF-36 scores.

Because the sense of smell is associated with several biological functions, including eating, reproduction, and avoidance of danger, OD leads to difficulties in daily living. Patients with severe hyposmia or anosmia have been shown to encounter significant impairment in health-related quality of life (16). Retrospective data has revealed that patients with OD are subject to reduced body weight, appetite, and psychological well-being, as well as an increased rate of depression (17).

Several olfaction-specific psychometric assessment tools have been developed to address the impact of $O D$ on daily life. Present Odor Perception Scale, which consists of three questions aiming to identify how well patients think they can smell, is one of the earliest questionnaires used for this purpose (18). QOD is another widely used psychometric assessment tool utilized to assess the quality of life related to OD (6). However, shortness of psychometrically validated instruments concerning self-reported general olfactory capability, self-reported capability of reporting specific odors and self-reported olfaction-related quality of life in patients with OD led to the development of novel psychometric assessment tools, such as the ASOF.

The ASOF has been shown to have excellent psychometric properties in addition to being easy to use in clinical practice. Therefore, the validity and reliability of the Turkish version of the ASOF were assessed for its application in subjects with OD. Our findings indicate that Turkish version of the ASOF is highly valid for assessment of the self-reported olfaction-related quality of life. The validity was assessed using both discriminant and convergent techniques. Discriminant validity was analyzed to determine the ASOF's discriminative power by comparing the ASOF score between healthy controls and patients with OD. Significant differences were found in ASOF-SOC, ASOF-SRP, and ASOF-ORO scores among participants with normosmia, hyposmia, and anosmia. These results support the findings published by Pusswald et al. (4), which showed significant differences in ASOF-SOC, ASOF-SRP, and ASOF-ORQ between subjects with $O D$ and healthy controls. This finding suggests that the Turkish version of the ASOF might be a valuable tool for discrimination of subjects with hyposmia from those with anosmia and subjects with hyposmia from those with normal olfactory function. Convergent validity was evaluated through correlation of the ASOF to Sniffin' Sticks test by using the data of the patients with OD. The TDI overall score and its subscales (T, D, and OI) had significant positive correlations with all ASOF subtests. The convergent validity of the Turkish version of the ASOF was also assessed by correlating ASOF subtest scores with other validated and commonly used psychometric tests, including SF-36 and $\mathrm{BDI}$, which measure similar or related concepts. ASOF subtests displayed significant positive correlations with overall SF-36 score and SF-36 domains, and negative correlations with BDI. Finally, the relation of the ASOF scales with age and sex in patients with OD was also investigated. The Turkish version of the ASOF was found to have no relation to age or sex.

\section{Study Limitations}

This study has limitations. Subjects with qualitative smell disorders, such as parosmia and phantosmia, were not enrolled in the study. Further studies enrolling patients with these disorders can further demonstrate the validity of the Turkish version of the ASOF in a larger population with OD. Nevertheless, given the high internal consistency and discriminant and convergent validity, we suggest that the Turkish version of the ASOF is highly valid and reliable to demonstrate subjective OD.

\section{CONCLUSION}

This study shows that the Turkish version of the ASOF is a reliable and valid measure to determine the impairment in daily life associated with OD. Its cost effective and easy-to-use feature makes the ASOF a useful tool for initial assessment and follow-up of patients with OD.

Ethics Committee Approval: Ethics committee approval was received for this study from the Ethics Committee of Medipol University (approval number: 268, date: 22.03.2019).

Informed Consent: Informed consent was obtained from all individual participants included in the study.

Peer-review: Externally peer-reviewed.

Author Contributions: Surgical and Medical Practices - Ö.S., Ö.A.D., A.A.; Concept - Ö.S., Ö.A.D.; Design - Ö.S., A.A.; Data Collection or Processing - Ö.S., Ö.A.D., A.A.; Analysis or Interpretation - Ö.S.; Literature Search - Ö.S., A.A.; Writing - Ö.S., Ö.A.D.

Conflict of Interest: No conflict of interest was declared by the authors.

Financial Disclosure: The authors declared that this study received no financial support.

\section{REFERENCES}

1. Brämerson A, Johansson L, Ek L, Nordin S, Bende M. Prevalence of olfactory dysfunction: the skövde population-based study. Laryngoscope 2004; 114: 733-7.

2. Keller A, Malaspina D. Hidden consequences of olfactory dysfunction: a patient report series. BMC Ear, Nose and Throat Disord 2013; 13: 8.

3. Croy I, Nordin S, Hummel T. Olfactory disorders and quality of life-an updated review. Chem Senses 2014; 39: 185-94.

4. Pusswald G, Auff E, Lehrner J. Development of a brief self-report inventory to measure olfactory dysfunction and quality of life in patients with problems with the sense of smell. Chemosensory Perception 2012; 5: 292-9

5. Neuland C, Bitter T, Marschner H, Gudziol H, Guntinas-Lichius O. Healthrelated and specific olfaction-related quality of life in patients with chronic functional anosmia or severe hyposmia. Laryngoscope 2011; 121: 867-72.

6. Croy I, Landis BN, Meusel T, Seo HS, Krone F, Hummel T. Patient adjustment to reduced olfactory function. Arch Otolaryngol Head Neck Surg 2011; 137: 377-82.

7. Frasnelli J, Hummel T. Olfactory dysfunction and daily life. Eur Arch Otorhinolaryngol 2005; 262: 231-5.

8. Tahmasebi R, Zehetmayer S, Stögmann E, Lehrner J. Awareness of olfactory dysfunction in subjective cognitive decline, mild cognitive 
decline, and Alzheimer's disease. Chemosensory Perception 2020; 13: 59-70.

9. Leonhardt B, Tahmasebi R, Jagsch R, Pirker W, Lehrner J. Awareness of olfactory dysfunction in Parkinson's disease. Neuropsychology 2019; 33: 633-41.

10. Hummel T, Sekinger B, Wolf SR, Pauli E, Kobal G. "Sniffin' sticks": olfactory performance assessed by the combined testing of odor identification, odor discrimination and olfactory threshold. Chem Senses 1997; 22: 39-52.

11. Kobal G, Klimek L, Wolfensberger M, Gudziol H, Temmel A, Owen C, et al. Multicenter investigation of 1,036 subjects using a standardized method for the assessment of olfactory function combining tests of odor identification, odor discrimination, and olfactory thresholds. Eur Arch Otorhinolaryngol 2000; 257: 205-11.

12. Ware JE Jr, Sherbourne CD. The MOS 36-item short-form health survey (SF-36). I. Conceptual framework and item selection. Med care 1992: 30: 473-83.
13. Koçyiğit H, Aydemir Ö, Fişek G, Ölmez N, Memiș A. Form-36 (KF-36)'nın Türkçe versiyonunun güvenilirliği ve geçerliliği. İlaç ve Tedavi Dergisi 1999; 12: 102-6.

14. Beck AT, Steer RA, Brown GK. Beck depression inventory-II. San Antonio 1996; 78: 490-8.

15. Hisli N. A Reliability and validity study of Beck Depression Inventory in a university students sample. J Psychol 1989; 7: 3-13.

16. Landis BN, Konnerth CG, Hummel T. A study on the frequency of olfactory dysfunction. Laryngoscope 2004; 114: 1764-9.

17. Deems DA, Doty RL, Settle RG, Moore-Gillon V, Shaman P, Mester AF, et al. Smell and taste disorders, a study of 750 patients from the University of Pennsylvania Smell and Taste Center. Arch Otolaryngol Head Neck Sur 1991; 117: 519-28.

18. de Jong N, Mulder I, de Graaf C, van Staveren WA. Impaired sensory functioning in elders: the relation with its potential determinants and nutritional intake. J Gerontol A Biol Sci Med Sci 1999; 54: B324-31. 